\title{
THE SURGICAL TECHNIQUE AND THE AGE OF THE HORSE BOTH INFLUENCE THE OUTCOME OF MOSAICPLASTY IN A CADAVER EQUINE STIFLE MODEL
}

\author{
G. BODÓ $^{1 *}$, A. D. KAPOSI ${ }^{2}$, L. HANGODY ${ }^{3}$, J. TÓTH ${ }^{1}$, Z. BAKOS ${ }^{4}$, Z. LuKÁCS ${ }^{1}$ \\ and G. PÉNTEK ${ }^{1}$
}

\begin{abstract}
${ }^{1}$ Department and Clinic of Surgery and Ophthalmology, Faculty of Veterinary Science, Szent István University, H-1400 Budapest, P.O. Box 2, Hungary; ${ }^{2}$ Institute of Biophysics and Radiation Biology, Semmelweis University, Budapest, Hungary; ${ }^{3}$ Orthopaedics and

Trauma Department, Uzsoki Hospital, Budapest, Hungary; ${ }^{4}$ Department of Internal

Medicine, Faculty of Veterinary Science, Szent István University, Budapest, Hungary
\end{abstract}

(Received May 10, 2000; accepted October 30, 2000)

\begin{abstract}
Six pieces of grafts, $6.5 \mathrm{~mm}$ in diameter, $20 \mathrm{~mm}$ in length, were taken from each of 170 cadaver hindlimbs, using the cranial surface of the medial femoral trochlea for harvesting. The age of the horses varied between 4 months and 23 years. 30 limbs under the age of 12 years were selected for transplantation. Three of six grafts were transplanted into the medial femoral condyle using different combinations of tunnel depth and dilation. With ageing, a significant decline in transplantability was detected. In general, mosaicplasty cannot be recommended in horses above 11 years. Based on a previous clinical case (Bodó et al., 2000), a good surface alignment was indeed achieved with a combination of graft length drilling and dilation in most cases. However, the occasional entrapment of cartilage debris under the graft prevented perfect alignment in the present cadaver study in $27 \%$ of the grafts transplanted in this manner. Since the protrusion of grafts never exceeded $1.5 \mathrm{~mm}$, we conclude that drilling 3-5 mm deeper than graft length with graft length deep dilation can avoid disadvantageous protrusion of the transplanted hyaline cartilage caps, achieving bone decompression at the same time.
\end{abstract}

Key words: Horses, autograft transplantation, mosaicplasty, stifle

Hyaline cartilage damage on the medial femoral condyle can lead to se condary joint injury and subsequent arthritis in horses (Schneider et al., 1997). Injured adult articular cartilage cannot regenerate and healing is, therefore, li mited (Ghadially, 1983a; Ghadially, 1983b; Vachon et al., 1986; Hurtig et al., 1988; Desjardins et al., 1991). Cartilage damage on the medial femoral condyle can result in subsequent secondary arthritis (Lewis, 1987; Stashak, 1987; Schneider et al., 1997).

*E-mail: gbodo@univet.hu; Fax: +36 (1) 478-4196 
A new hyaline cartilage transplantation method, called mosaicplasty (MP), has been developed and used in the last decade for human knee joint resurfac ement with results superior to those of prior methods ( Matsusue et al., 1993; Hangody, 1997; Hangody et al., 1997a; Hangody et al., 1997b; Kish et al., 1999). The first report using MP in horses has recently been published on the treatment of subchondral cystic lesion in the medial femoral condyle ( Bodó et al., 2000). Applying the human orthopaedic experience to the treatment of equine joint di sorders seems to be desirable. However, a substantial difference between humans and horses is the inability to avoid immediate postoperative weight-bearing in the latter. In an animal trial using German Shepherd dogs with immediate pos toperative weight-bearing, a high percentage of disadvantageous graft subsidence was reported (Hangody et al., 1997c). A good surface alignment was achieved with graft-length drilling and dilatation in the above-mentioned case report (Bodó et al., 2000).

Inspired by the preliminary experience of this single case, the purpose of the study was to further develop the technique and observe the results of diffe rent implantation methods on a cadaver serial. Preliminary data suggested that older horses could not yield a suitable bone graft. Therefore, we performed a study considering also the age of cadavers.

\section{Materials and methods}

Six pieces of cylindrical osteochondral grafts, $20 \mathrm{~mm}$ long, spaced $5 \mathrm{~mm}$ from each other, were taken from the cranial aspect of the medial femoral troc hlea (Fig. 1) of 170 cadaver femurs. A 6.5-mm tubular chisel (Metrimed Kft. Hódmezővásárhely, Hungary), held meticulously perpendicular to the joint su rface, was used for harvesting. Harvesting was always carried out by the same experienced surgeon. Horses were grouped into four arbitrary age groups: Group A: 4 months -2 years; Group B: 3-8 years; Group C: 9-12 years and Group D: 13 years and older. The age ranged from 4 months to 23 years. Breed, sex, and usage (active training or paddock exercise) were also noted. In each individual horse, both hindlimbs were evaluated and scored 1-3 for the ability to obtain a suitable graft.

From each of Groups A, B and C, ten limbs were selected for transplant ation. The only criterion for inclusion was the ability to harvest all six grafts in a transplantable condition. Subsequently, three of the six grafts were transplanted to the medial femoral condyle of the same limb using our protocol described b elow. The procedure was carried out on fresh, open cadaver stifle joints. The first graft was inserted into the medial femoral condyle in a manner similar to that used in the human practice (Hangody et al., 1997a; Hangody et al., 1997b; Hangody et al., 1998; Kish et al., 1999), in that both recipient holes and dilation 
measured $40 \mathrm{~mm}$ in depth. The second graft was placed in a 40-mm deep recip ient hole after a $20 \mathrm{~mm}$-deep dilation, while for the third graft, 20-mm deep drilling and 20-mm deep dilation was used. Recipient holes were placed at a 5$\mathrm{mm}$ distance from each other along a virtual line perpendicular to the limb axis (Fig. 2). The grafts were inserted into the dilated holes under permissible load. After alignment of the hyaline cap of the grafts with the joint surface, permiss ible load was continued with a surgical hammer, using a delivery tamp. If the graft hyaline cap could not reach the joint surface, the distance was assigned a negative value. For exact measurement, the condyles were dissected in the mi dline of the inserted graft channels in two halves with a bone saw (Fig. 3).

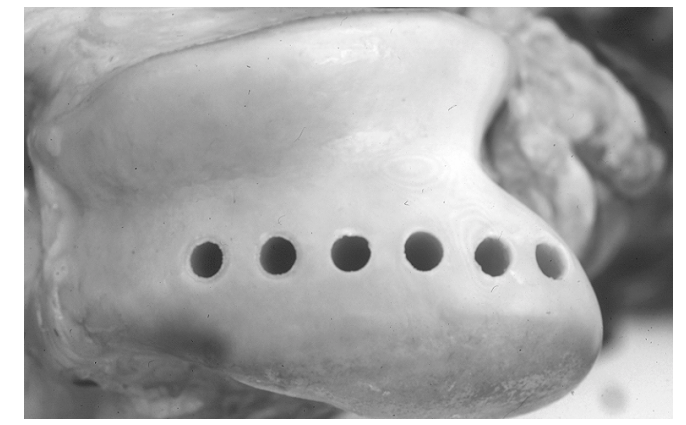

Fig. 1. Donor site. The cranial surface of the medial femoral trochlea was selected for harvesting
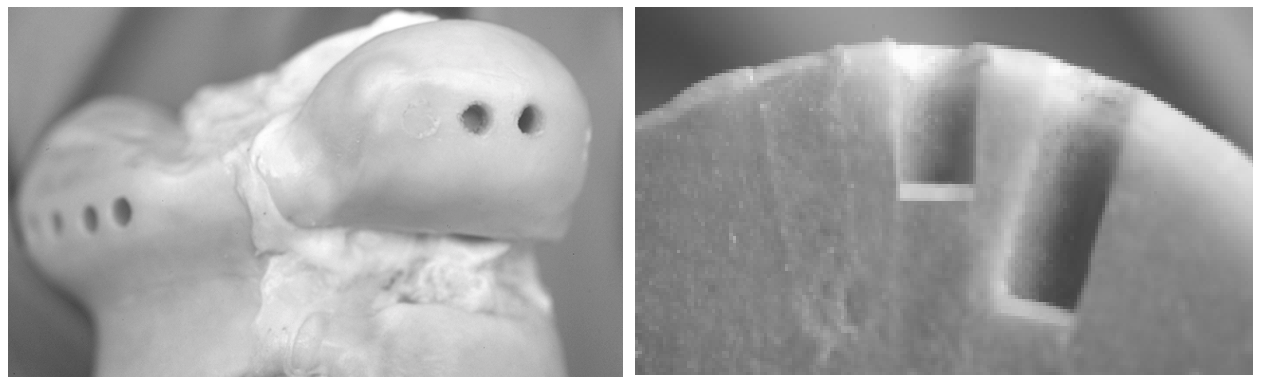

Fig. 2. Recipient area. Three grafts were implanted into the medial femoral condyle as described in the text. A cross-section is shown in Fig. 3

Fig. 3. Cross-section of the recipient area with the transplanted grafts shown in Fig. 2

The relation between age and transplantability was analysed statistically using a $t$ test of the correlation coefficient. Significance was set at $\mathrm{P}<0.05$ (or less), and results are reported as mean $\pm \mathrm{SD}$. 


\section{Results}

There was no significant difference between the number of harvested healthy grafts on the left (mean $\pm \mathrm{SD}, 5.28 \pm 1.47)$ and right $(5.28 \pm 1.46)$ limbs, when all four groups were combined. Separation of the groups yielded the same conclusion. Removing the grafts was easy (score 1) until the age of 2 years, but above that age harvesting became difficult (score 3 ) in all cases.

There was a significant correlation $(p<0.01 \%)$ between the age of the horses and the number of harvested transplantable grafts. A significant difference was found between the number of harvested transplantable grafts of horses with active training and those kept in paddock. In horses under active training, at least 10 of 12 harvested grafts were in transplantable condition (95\% probability) up to 15 years of age. However, this age limit decreased to 11 and 8.3 if the whole population, or horses kept in paddock were examined, respectively. In $92 \%$ of the unsuitable grafts, the subchondral region was fractured (Fig. 4), while flattening of the graft hyaline cap was seen in the remaining $8 \%$. Horses in bad overall cond ition appeared to have unacceptable grafts more often than those in good co ndition.

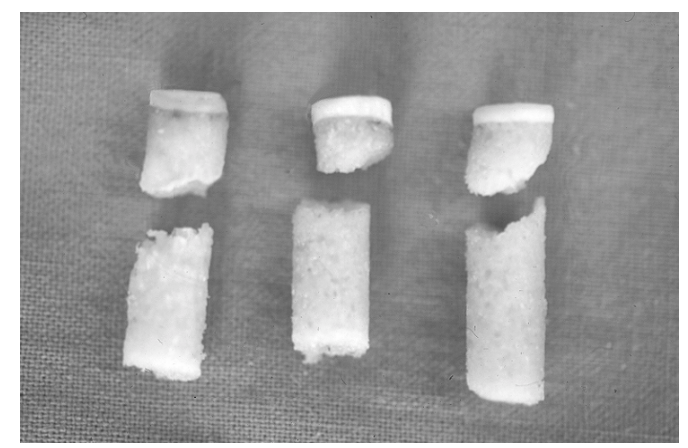

Fig. 4. Unsuitable grafts. The subchondral region is fractured

Implantation of the grafts with permissible load into deep $(40 \mathrm{~mm})$ recip ient holes gave easy subsidence under the joint surface. The subsidence measured from the joint surface was $19 \pm 1.2 \mathrm{~mm}, 13.8 \pm 2 \mathrm{~mm}$, and $0.7 \pm 1 \mathrm{~mm}$ in the first (40 $\mathrm{mm}$ drilling and dilating), second (40 mm drilling and $20 \mathrm{~mm}$ dilating) and third (20 mm drilling and dilatation) groups, respectively.

\section{Discussion}

Under the age of 30,90\% of human athletes undergoing MP treatment for various focal chondral and osteochondral defects in the knee and talus return to competition. If athletes under 50 are considered, this value decreases to $63 \%$ 
(Kish et al., 1999). Based on the results of this cadaver study, it can be said that up to around 15 years of age, it is still possible to perform mosaic arthroplasty in the 'horse athlete'. For horses kept in paddock, a lower age cut-off of 11 is su ggested. To answer the question about the age optimum for mosaic arthroplasty on horses, obviously, further experimental studies are required.

Based on a previous clinical case (Bodó et al., 2000), a good surface alignment was indeed achieved with a combination of graft-length drilling and dilation in $73 \%$ of the grafts transplanted in this manner. However, in the $\mathrm{r}$ emaining $27 \%$, the graft caps protruded $0.5-1.5 \mathrm{~mm}$ from the plane of the joint surface (Fig. 5), a technical problem evidently caused by the occasional entra pment of cartilage debris.

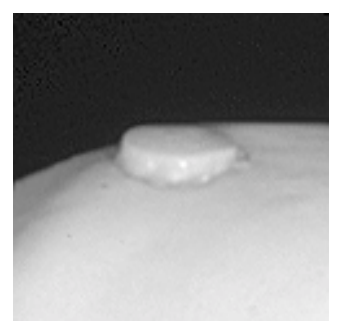

Fig. 5. Unsatisfactory subsidence of the graft hyaline cap $(-1.5 \mathrm{~mm})$

Degenerative changes in the joint are often associated with an elevated i ntraosseal pressure, which can be decreased by subchondral drilling ( Insall, 1967; Mitchell and Shephard, 1976; Galloway and Noyes, 1992) or by the MP procedure with a few mm deeper than graft-length drilling ( Hangody, 1994).

Since the protrusion of grafts never exceeded $1.5 \mathrm{~mm}$, we conclude that drilling 3-5 $\mathrm{mm}$ deeper than graft length with graft-length deep dilation can avoid disadvantageous protrusion of the transplanted hyaline cartilage caps, achieving bone decompression at the same time. This hypothesis has been proved after completion of this cadaver study in live horses which resulted in no subsidence of the transplanted grafts (to be published elsewhere).

\section{Acknowledgements}

The authors would like to express their gratitude to Mr. I. Bodó and Ms. K. Endrődi for their invaluable technical assistance as well as to Mrs. Józsefné Kampó for preparing the illustrations, and the Department of Pathology for providing the limbs. 


\section{References}

Bodó, G., Hangody, L., Szabó, Zs., Peham, Ch., Schinzel, M., Girtler, D. and Sótonyi, P. (2000): Arthroscopic autologous osteochondral mosaicplasty for the treatment of subchondral cystic lesion in the medial femoral condyle in a horse. Acta Vet. Hung. 48, 343-354.

Desjardins, M. R., Hurtig, M. B. and Palmer, N. C. (1991): Heterotopic transfer of fresh and cryopreserved autogenous articular cartilage in the horse. Vet. Surg. 20, 434-445.

Galloway, M. T. and Noyes, F. R. (1992): Cystic degeneration of the patella after arthroscopic chondroplasty and subchondral bone perforation. Arthroscopy 8, 366-369.

Ghadially, F. N. (1983a): Superficial (partial-thickness) defects and other injuries in articular cartilage. In: Ghadially, F. N. (ed.) The Fine Structure of Synovial Joints. Butterworths, London. pp. 261-279.

Ghadially, F. N. (1983b): Deep (full-thickness) defects in articular cartilage. In: Ghadially, F. N. (ed.) The Fine Structure of Synovial Joints. Butterworths, London. pp. 280-306.

Hangody, L. (1994): The surgical treatment of knee chondropathy I and II (in Hungarian). PhD Dissertation, Budapest, Uzsoki Press.

Hangody, L. (1997): Mosaicplasty in the chondral resurfacement. Wellington Knee Meeting Book of the Lectures - London, UK.

Hangody, L., Kish, G., Kárpáti, Z. and Eberhardt, R. (1997a): Osteochondral plugs: autogenous osteochondral mosaicplasty for the treatment of focal chondral and osteochondral articular defects. Operative Techniques in Orthopaedics 7, 312-322.

Hangody, L., Kish, G., Kárpáti, Z., Szerb, I. and Udvarhelyi, I. (1997b): Arthroscopic autogenous osteochondral mosaicplasty for the treatment of femoral condylar articular defects. A preliminary report. Knee Surg. Sports Traumat. Arthrosc. 5, 262-267.

Hangody, L., Kish, G., Kárpáti, Z., Szerb, I., Udvarhelyi, I., Tóth, J., Diószegi, Z. and Kendik, Zs. (1997c): Autogenous osteochondral graft technique for replacing knee cartilage defects in dogs. Orthopaedics International Edition 5, 175-181.

Hangody, L., Kish, G., Kárpáti, Z., Udvarhelyi, I., Szigeti, I. and Bély, M. (1998): Mosaicplasty for the treatment of articular cartilage defects: application in clinical practice. Othopedics 21, 751-756.

Hurtig, M. B., Fretz, P. B., Doige, C. E. and Schnurr, D. L. (1988): Effects of lesion size and location on equine articular cartilage repair. Can. J. Vet. Res. 52, 137-146.

Insall, J. N. (1967): Intra-articular surgery for degenerative arthritis of the knee. A report of the work of the late K. H. Pridie. J. Bone Joint Surg. Br. 49, 211-228.

Kish, G., Módis, L. and Hangody, L. (1999): Osteochondral mosaicplasty for the treatment of focal chondral and osteochondral lesions of the knee and talus in the athlete. Clinics in Sports Medicine 18, 45-66.

Lewis, R. D. (1987): Retrospective study of diagnostic and surgical arthroscopy of the equine femorotibial joint. In: Proceedings of Am. Assoc. Equine Pract. Annu. Meet. pp. 887-893.

Matsusue, Y., Yamainuro, T. and Hama, H. (1993): Arthroscopic multiple osteochondral transplantation to the chondral defect in the knee associated with anterior cruciate ligament disruption: case report. Arthroscopy 9, 318-321.

Mitchell, N. and Shephard, N. (1976): The resurfacing of adult rabbit articular cartilage by multiple perforations through the subchondral bone. J. Bone Joint Surg. A 58, 230-233.

Schneider, R. K., Jenson, P. and Moore, R. M. (1997): Evaluation of cartilage lesions on the medial femoral condyle as a cause of lameness in horses: 11 cases (1988-1994). J. Am. Vet. Med. Assoc. 210, 1649-1652.

Stashak, T. S. (1987): Lameness of the stifle joint (gonitis). In: Stashak, T. S. (ed.) Lameness in Horses. 4th ed. Lea \& Febiger, Philadelphia, pp. 733-737.

Vachon, A., Bramlage, L. R., Gabel, A. A. and Weisbrode, S. (1986): Evaluation of the repair process of cartilage defects of the equine third carpal bone with and without subchondral bone perforation. Am. J. Vet. Res. 47, 2637-2645. 